\title{
Synthesis of $\mathrm{Eu}^{2+}$ and $\mathrm{Dy}^{3+}$ Doped Strontium Aluminates and Their Properties
}

\author{
Laura Rozenberga-Voska ${ }^{1, a^{*}}$, Janis Grabis ${ }^{1, b}$, Aleksejs Zolotarjovs ${ }^{2, c}$ \\ ${ }^{1}$ Institute of Inorganic Chemistry, Faculty of Material Science and Applied Chemistry, Riga \\ Technical University, Paula Valdena Street 3/7, Riga, LV-1048, Latvia ${ }^{2}$ Institute of Solid State \\ Physics, University of Latvia, Kengaraga Street 8, Riga, LV-1063, Latvia \\ alaura.rozenberga@gmail.com, bjgrabis@rtu.lv, calexeyzolotarjov@gmail.com
}

Keywords: strontium aluminate phosphors, luminescence, solution combustion method, specific surface area, powder XRD.

\begin{abstract}
Strontium aluminate phosphors were synthesized by the solution combustion method using citric acid, urea or glycine as reducing agent and europium and dysprosium as dopants. The content of both dopants was in the range of $1-2$ mol\%. Dependence of phase composition, crystallite size and specific surface area on calcinations temperature, used reducing agents and dopants were determined. Luminescent properties of the calcinated at $1300{ }^{\circ} \mathrm{C}$ powders contained $\mathrm{SrAl}_{2} \mathrm{O}_{4}(90 \%)$ and $\mathrm{Sr}_{4} \mathrm{Al}_{24} \mathrm{O}_{25}(10 \%)$ phases with crystallite size of $80 \mathrm{~nm}$ were determined.
\end{abstract}

\section{Introduction}

Last years the luminescent properties of $\mathrm{SrO}-\mathrm{Al}_{2} \mathrm{O}_{3}-\mathrm{Eu}-\mathrm{Dy}$ system have attracted much attention [1]. Strontium aluminates doped with rare earth ions were observed to be efficient light emitter and found many applications as long afterglow phosphors [2]. They are used in safety and emergency signs, in plasma screens, fluorescent lamps and light diodes. Strontium aluminates occur in several stoichiometries, for example $\mathrm{SrAl}_{12} \mathrm{O}_{19}, \mathrm{SrAl}_{4} \mathrm{O}_{7}, \mathrm{Sr}_{4} \mathrm{Al}_{14} \mathrm{O}_{25}, \mathrm{SrAl}_{2} \mathrm{O}_{4}$ and $\mathrm{Sr}_{3} \mathrm{Al}_{2} \mathrm{O}_{6}$, arranged according to an increasing molar ratio of $\mathrm{SrO}_{2} \mathrm{Al}_{2} \mathrm{O}_{3}$ [3]. The most researches in strontium aluminate phases are related with the strong green emision $(\sim 530 \mathrm{~nm})$ of $\mathrm{Eu}^{2+}$ in stoichiometric $\mathrm{SrAl}_{2} \mathrm{O}_{4}$ with monoclinic trydimite structure [4].

The long persistent luminescence mechanism of the rare earth doped ions have been explained by many researchers in their own views [5-8]. However, there is no comprehensive understanding of the luminescence mechanisms and the development of new materials is very often based on trial and error methods [9].

Luminescent properties of strontium aluminate depend on their phase composition, particle size, used dopants, and therefore on the preparation method. Several preparation methods of strontium aluminates such as solid state, liquid and gas phase processes have been elaborated. Among these methods combustion synthesis are very promising [10]. However a little is known about influence of reducing agents on phase composition, particle size of strontium aluminates.

In this study the influence of reducing agents (citric acid, glycine, urea) on the parameters and luminescent properties of the prepared by combustion synthesis was investigated.

\section{Experimental}

Strontium aluminate phosphors doped with $\mathrm{Eu}^{2+}$ and $\mathrm{Dy}^{3+}$ were prepared by the reaction between strontium nitrate $\left(\mathrm{Sr}\left(\mathrm{NO}_{3}\right)_{2}\right)$, aluminium nitrate hexahydrate $\left(\mathrm{Al}\left(\mathrm{NO}_{3}\right)_{3} \cdot 6 \mathrm{H}_{2} \mathrm{O}\right)$, europium nitrate hexahydrate $\left(\mathrm{Eu}\left(\mathrm{NO}_{3}\right)_{3} \cdot 6 \mathrm{H}_{2} \mathrm{O}\right)$, dysprosium(III) oxide $\left(\mathrm{Dy}_{2} \mathrm{O}_{3}\right)$ and organic combustion agents - urea $\left(\mathrm{CO}\left(\mathrm{NH}_{2}\right)_{2}\right)$, glycine $\left(\mathrm{C}_{2} \mathrm{H}_{5} \mathrm{NO}_{2}\right)$, citric acid $\left(\mathrm{C}_{6} \mathrm{H}_{8} \mathrm{O}_{7} \cdot \mathrm{H}_{2} \mathrm{O}\right)$. Small amount of boric acid $\left(\mathrm{H}_{3} \mathrm{BO}_{3}\right)$ was used as flux. The stoichiometric compositions were calculated using total oxidizing and reducing valences. The doping concentrations of the $\mathrm{Eu}^{2+}$ and $\mathrm{Dy}^{3+}$ ions were 1 and 1,1 and 2, 2 and 1,2 and 2 mol\%, respectively. 
The starting materials were dissolved in deionised water $\left(\mathrm{Dy}_{2} \mathrm{O}_{3}\right.$ in diluted nitric acid) and stirred on the hotplate until the transparent solution boiled and underwent dehydratation.

After stirring the solution was taken into a furnace maintained at a temperature of $600^{\circ} \mathrm{C}$. Spontaneous ignition occurred and underwent smouldering combustion, producing foamy and voluminous ash.

The prepared powders were homogenised in pestle, splitted in 3 parts and calcinated at $900^{\circ} \mathrm{C}$, $1000{ }^{\circ} \mathrm{C}$ and $1300{ }^{\circ} \mathrm{C}$ temperature for $2 \mathrm{~h}$. After the calcination, powders were homogenized again and treated in a protective $\mathrm{N}_{2}$ atmosphere at $900{ }^{\circ} \mathrm{C}$ temperature for $1 \mathrm{~h}$.

Phase identification, crystallite size and phase content calculation were carried out using a Bruker D8 Advance X-ray diffractometer equipped with Topas 4.1 software. The specific surface of powders was determined by argon adsorbtion-desorbtion method. SEM (scanning electron microscopy) pictures were obtained by the Tescan Lyra microscope. Photoluminiscence was excited by using $266 \mathrm{~nm}$ laser. The luminescence spectra was detected by using CCD camera Andor DU401_BV connected to Andor SR303i monochromator.

\section{Results and discussion}

Strontium aluminates were synthesized by the combustion method using urea, glycine and citric acid as reducing agents. Combustion processes went differently depending on the organic matter. Using urea the reaction mixture rapidly foamed and burned with orange flame and popping sound. Obtained precursor powder was white and fluffy. Combustion reaction with citric acid gave medium flame and black powder was obtained. Using glycine the reaction was less intense than in the case of urea or citric acid. Obtained powder was light brown. Colour of the as-prepared samples was connected with presence of decomposition products of organic compounds depending on reaction intensity and temperature. Further calcination was needed to get rid of black and brown powder colour as well as trying to get the single phase strontium aluminate.

Phase analysis. Calcination at $900{ }^{\circ} \mathrm{C}$ temperature is insufficient to get a single phase of strontium aluminate or at least one predominating phase. Mixed $\mathrm{SrAl}_{2} \mathrm{O}_{4}, \mathrm{SrAl}_{4} \mathrm{O}_{7}, \mathrm{Sr}_{3} \mathrm{Al}_{2} \mathrm{O}_{6}$ phases were observed. Increased background line means that powder is partially amorphous.

Calcination at $1000{ }^{\circ} \mathrm{C}$ leads to increasing of $\mathrm{SrAl}_{2} \mathrm{O}_{4}$ phase and it can be considered as predominating.

Samples calcinated at $1300{ }^{\circ} \mathrm{C}$ contain $\mathrm{SrAl}_{2} \mathrm{O}_{4}(90 \%)$ and $\mathrm{Sr}_{4} \mathrm{Al}_{14} \mathrm{O}_{25}(10 \%)$.

Regardless of used organic combustion agents, in all cases X-ray diffraction patterns of samples calcinated in high temperatures do not change significantly (Fig. 1).

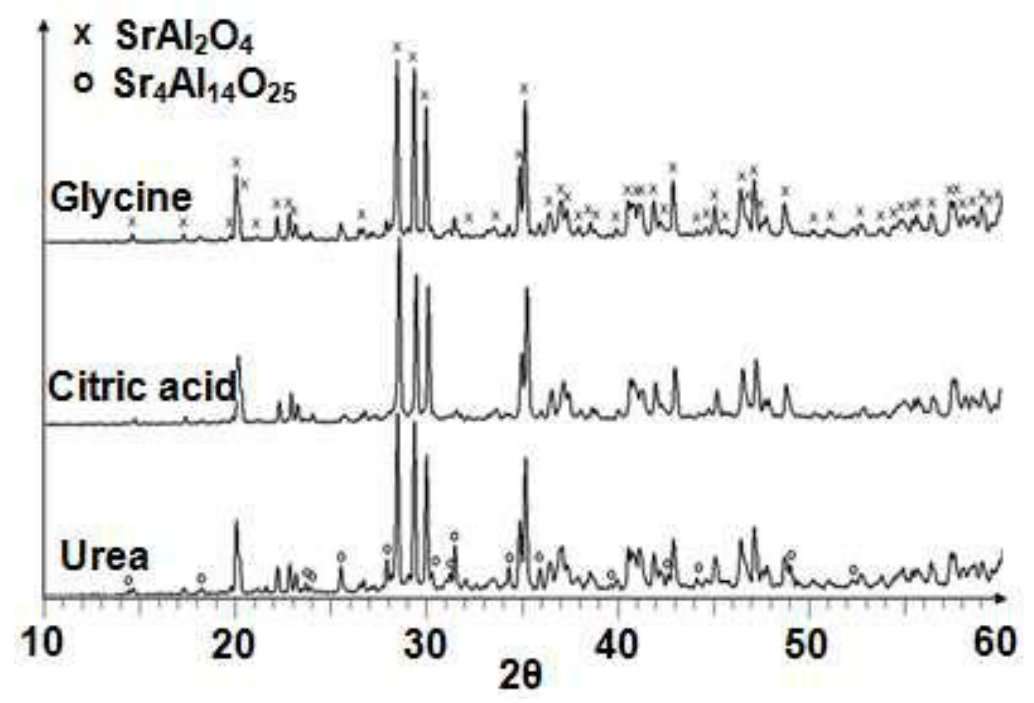

Fig. 1. XRD patterns of strontium aluminate synthesized using different combustion agents and calcinated at $1300^{\circ} \mathrm{C}$. 
Surface morphology, specific surface area and crystallite size. Figure 2 shows SEM micrographs. The strontium aluminate powders consisted from irregular agglomerated particles, partially sintered due high calcinations temperature. Particle micrographs obtained at higher magnification showed that agglomerates involved smaller particles with various shapes.

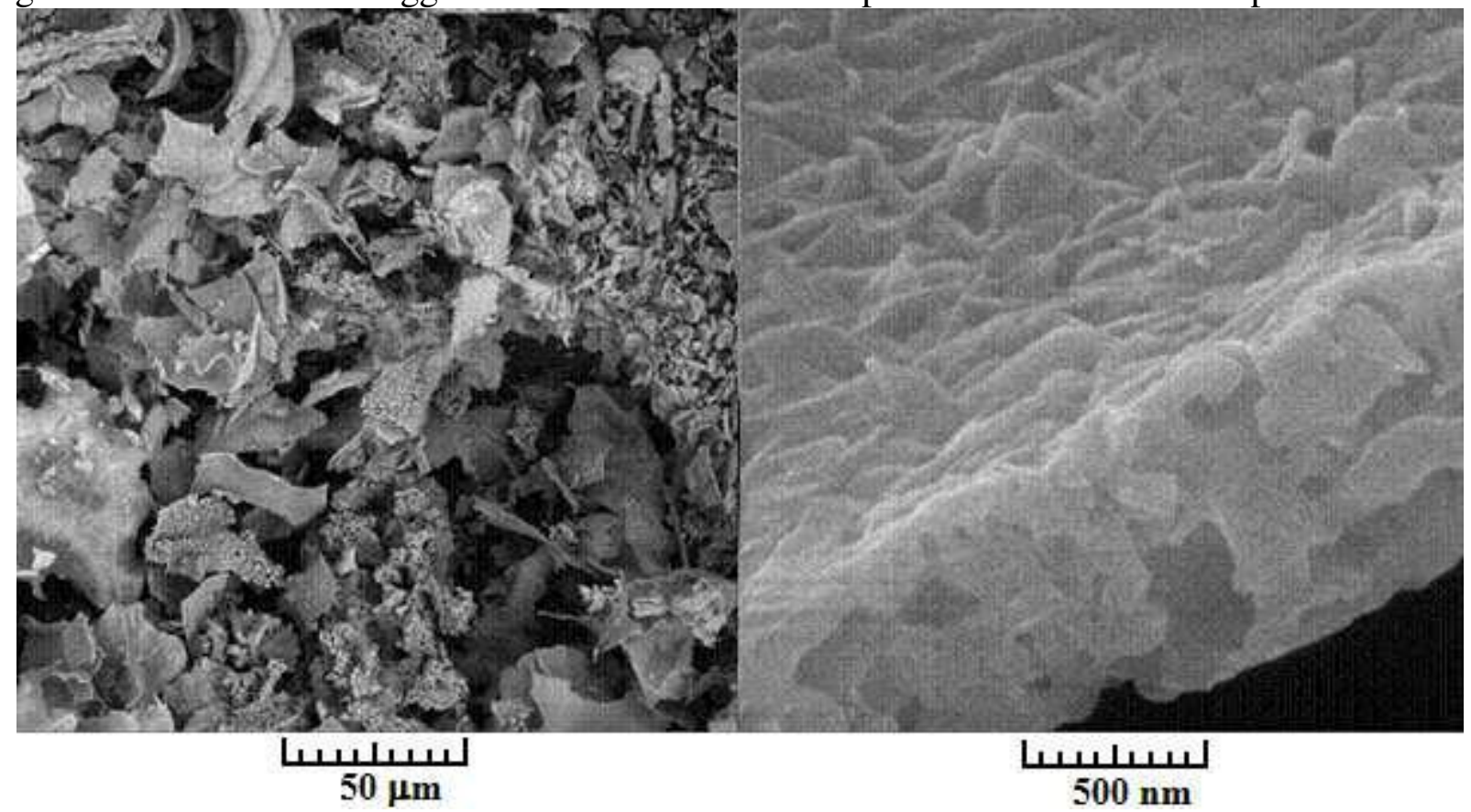

Fig. 2. SEM images of $\mathrm{SrAl}_{2} \mathrm{O}_{4}: \mathrm{Eu}^{2+}, \mathrm{Dy}^{3+}, \mathrm{Sr}_{4} \mathrm{Al}_{14} \mathrm{O}_{25}: \mathrm{Eu}^{2+}, \mathrm{Dy}^{3+}$, prepared by using urea, 1 $\mathrm{mol} \% \mathrm{Eu}, 1 \mathrm{~mol} \%$ Dy and calcinated at $1300{ }^{\circ} \mathrm{C}$.

The results of measured specific surface area are summarized in Table 1. Samples treated at $900{ }^{\circ} \mathrm{C}$ have a specific surface area in the range from 12 to $39 \mathrm{~m}^{2} / \mathrm{g}$. Increasing calcination temperature the specific surface area decreases. At $1300{ }^{\circ} \mathrm{C}$ the surface is $6-9 \mathrm{~m}^{2} / \mathrm{g}$. The higher specific surface have strontium aluminate samples synthesized using citric acid, because lower reaction rate and presence of decomposition products.

Crystallite size varies from 20 to $30 \mathrm{~nm}$ for samples calcinated at $900{ }^{\circ} \mathrm{C}, 50-60 \mathrm{~nm}$ at $1000{ }^{\circ} \mathrm{C}$ and approximately $80 \mathrm{~nm}$ at $1300^{\circ} \mathrm{C}$. Increasing of heating temperature promotes increasing the particle size of strontium aluminate due to particle growth and partial sintering of agglomerates.

Table 1. Specific surface area of strontium aluminate samples synthesized using different combustion agents and calcinating temperatures.

\begin{tabular}{|c|c|c|c|c|c|}
\hline \multirow{2}{*}{ Combustion } & Temperature of & \multicolumn{4}{|c|}{ Specific surface area, ${ }^{2} / \mathrm{g}$} \\
\hline \multirow{3}{*}{ agent } & calcination, ${ }^{\circ} \mathrm{C}$ & $\begin{array}{c}1 \% \mathrm{Eu}, \\
1 \% \mathrm{Dy}\end{array}$ & $\begin{array}{c}1 \% \mathrm{Eu}, \\
2 \% \mathrm{Dy}\end{array}$ & $\begin{array}{c}2 \% \mathrm{Eu}, \\
1 \% \mathrm{Dy}\end{array}$ & $\begin{array}{c}2 \% \mathrm{Eu}, \\
2 \% \mathrm{Dy}\end{array}$ \\
\hline \multirow{3}{*}{ Urea } & 900 & 11,9 & 17,4 & 19,5 & 17,3 \\
\cline { 2 - 6 } & 1000 & 8,1 & 12,4 & 16,2 & 15,7 \\
\cline { 2 - 6 } & 1300 & 5,7 & 9,4 & 6,9 & 7,7 \\
\hline \multirow{3}{*}{ Gitric acid } & 900 & 38,9 & 18,3 & 37,7 & 37,1 \\
\cline { 2 - 6 } & 1000 & 24,4 & 10,3 & 27,2 & 26,6 \\
\hline & 1300 & 6,0 & 9,9 & 7,4 & 7,2 \\
\cline { 2 - 6 } & 900 & 21,9 & 24,5 & 25,1 & 23,9 \\
\cline { 2 - 6 } & 1000 & 20,7 & 23,2 & 18,5 & 24,1 \\
\hline
\end{tabular}


Luminescent properties. For photoluminiscence measurements samples calcinated at $1300{ }^{\circ} \mathrm{C}$ with definite phase composition $\mathrm{SrAl}_{2} \mathrm{O}_{4}: \mathrm{Eu}^{2+}, \mathrm{Dy}^{3+}(90 \%)$ and $\mathrm{Sr}_{4} \mathrm{Al}_{14} \mathrm{O}_{25}: \mathrm{Eu}^{2+}, \mathrm{Dy}^{3+}(10 \%)$ were chosen. Emission spectra at room temperature showed broad centred on $525 \mathrm{~nm}$ and several peaks at $575-675 \mathrm{~nm}$ and $690-715 \mathrm{~nm}$ were observed. The broad maxima in the range of $400-650 \mathrm{~nm}$ corresponds emission spectra of $\mathrm{SrAl}_{2} \mathrm{O}_{4}: \mathrm{Eu}^{2+}$ and $\mathrm{Sr}_{4} \mathrm{Al}_{14} \mathrm{O}_{25}: \mathrm{Eu}^{2+}$ [9]. Sharp peaks in the range of 575 - $675 \mathrm{~nm}$ will be connected with Eu2+, Eu3+ and Dy3+ luminescence, for example Eu3+ luminescence was observed in the Range of $570-600 \mathrm{~nm}\left(5 \mathrm{D}_{0} \rightarrow{ }^{7} \mathrm{~F}_{1}\right)$ and in the range of $600-640 \mathrm{~nm}$ $\left(5 \mathrm{D}_{0} \rightarrow{ }^{7} \mathrm{~F}_{2}\right)$. However, the identification of the mentioned peaks demands more detailed studies.

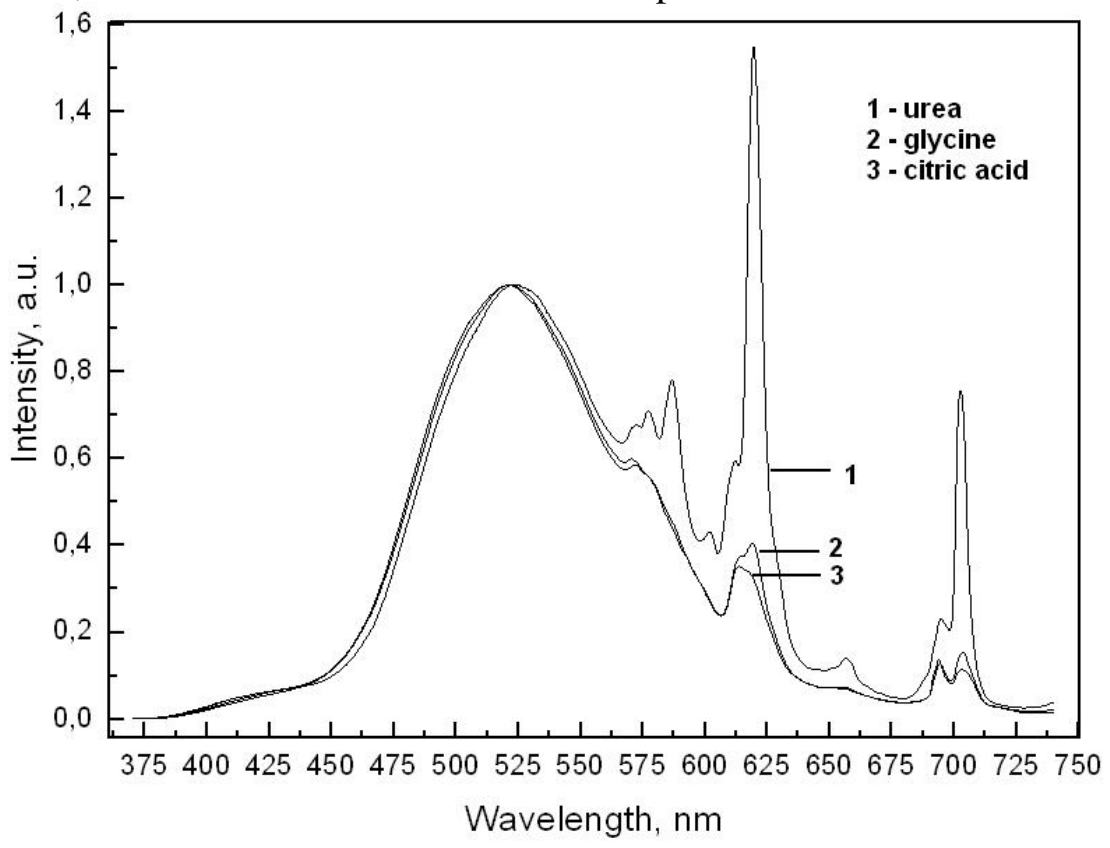

Fig. 3. Emission spectra of $\mathrm{SrAl}_{2} \mathrm{O}_{4}: \mathrm{Eu}^{2+}, \mathrm{Dy}^{3+}, \mathrm{Sr}_{4} \mathrm{Al}_{14} \mathrm{O}_{25}: \mathrm{Eu}^{2+}, \mathrm{Dy}^{3+}$ radiation source $266 \mathrm{~nm}$ laser.

The luminescence afterglow decay curves of $\mathrm{SrAl}_{2} \mathrm{O}_{4}: \mathrm{Eu}^{2+}, \mathrm{Dy}^{3+}$ phosphor doped with various amounts of $\mathrm{Eu}^{2+}$ and $\mathrm{Dy}{ }^{3+}$ ions are presented in Fig. 4. When doped $\mathrm{Eu}^{2+}$ concentration was 1 mol\% and co-doped $\mathrm{Dy}^{3+}$ was $1 \mathrm{~mol} \%$, the phosphor exhibited the highest luminescence intesity. However, rapid luminescence decay was observed.

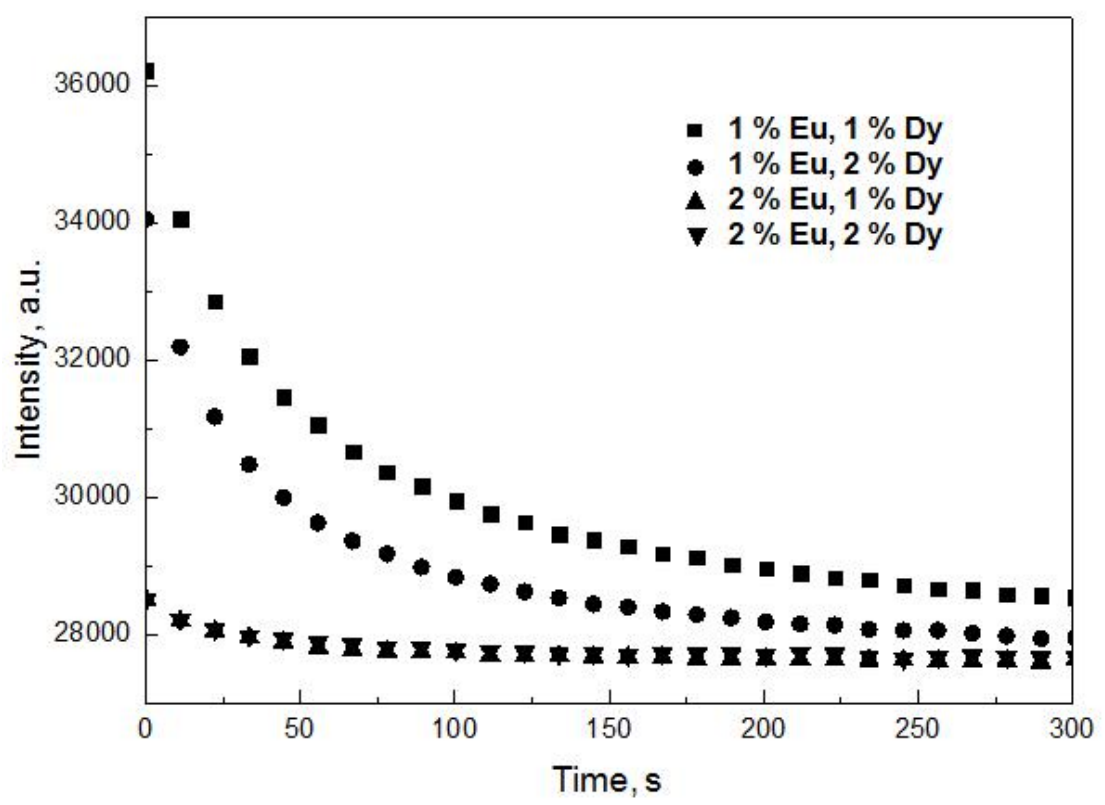

Fig. 4. Luminescence decay curves of $\mathrm{SrAl}_{2} \mathrm{O}_{4}: \mathrm{Eu}^{2+}, \mathrm{Dy}^{3+}, \mathrm{Sr}_{4} \mathrm{Al}_{14} \mathrm{O}_{25}: \mathrm{Eu}^{2+}, \mathrm{Dy}^{3+}$ with different dopant concentrations 


\section{Summary}

1. Combining combustion synthesis and thermal treatment the nanoparticles of rare earth ions doped strontium aluminate were performed having a specific surface area in the range from 5,7 to $38,9 \mathrm{~m}^{2} / \mathrm{g}$ and crystallite size from 20 to $80 \mathrm{~nm}$ depending on the calcinations temperature. Calcinated at $1300{ }^{\circ} \mathrm{C}$ powder contained $\mathrm{SrAl}_{2} \mathrm{O}_{4}: \mathrm{Eu}^{2+}, \mathrm{Dy}^{3+}(90 \%)$ and $\mathrm{Sr}_{4} \mathrm{Al}_{14} \mathrm{O}_{25}: \mathrm{Eu}^{2+}, \mathrm{Dy}^{3+}(10 \%)$ phases.

2. The specific surface area and crystallite size of as-prepared powders depend on used organic reducing agent, determined reaction intensity and amount of decomposition products.

3. The luminiscence intensity were highest for samples containing smaller dopant concentrations (1 $\mathrm{mol} \% \mathrm{Eu}$ and $1 \mathrm{~mol} \%$ Dy).

\section{Acknowledgments}

Financial support to this project was provided by National Research Programme (IMIS ${ }^{2}$ ).

\section{References}

[1] M. V. S. Rezende, P. J. R. Montes, F. M. S. Soares, C. Santos, M. E. G. Valerio, Influence of co-dopant in the europium reduction in $\mathrm{SrAl}_{2} \mathrm{O}_{4}$ host, J. Synchrotron Rad. 21 (2014) 143-148.

[2] A. Lakshmanan, Luminiscence and Display Phosphors: Phenomena and Applications, Nova Science Publishers, New York, 2008, pp 9, 274.

[3] P. Ptacek, Strontium Aluminate - Cement Fundamentals, Manufacturing, Hydration, Setting Behaviour and Applications, InTech, Rijeka, 2014, pp 4-9.

[4] D. Haranath, S. Virendra, C. Harish, S. Pooja, Tuning of Emission Colours in Strontium Aluminate Long Persisting Phosphor, Journal of Physics D: Applied Physics 36 (2003) 2244-2248.

[5] T. Matsuzawa, Y. Aoki, N. Takeuchi, Y. Murayama, A new long phosphorescent phosphor with high brightness, $\mathrm{SrAl}_{2} \mathrm{O}_{4}: \mathrm{Eu}^{2+}, \mathrm{Dy}^{3+}$, J. Electrochem. soc. 143 (1996) 2670-2673.

[6] T. Aitasalo, J. Holsa, H. Jungner, M. Lastusaari, J. Niittykoski, Mechanisms of persistent luminescence in $\mathrm{Eu}^{2+}, \mathrm{RE}^{3+}$ doped alkaline earth aluminates, J. Lumines. 94 (2001) 94-95.

[7] P. Dorenbos, Mechanism of persistent luminescence in $\mathrm{Eu}^{2+}$ and $\mathrm{Dy}^{3+}$ codoped aluminate and silicate compounds, J. Electrochem. Soc. 152 (2005) H107-H110.

[8] F. Clabau, X. Rocquefelte, S. Jobic, P. Deniard, M. H. Whangbo, A. Garcia, T. Le Mercier, On the phosphorescence mechanism in $\mathrm{SrAl}_{2} \mathrm{O}_{4}: \mathrm{Eu}^{2+}$ and its codoped derivatives, Solid State Sci. 9 (2007) 608-612.

[9] D. Dutczak, $\mathrm{Eu}^{2+}$ activated persistent luminiscent materials, Doctoral Thesis, Debye Institute, University of Utrecht, 2013.

[10]A. Lakshmanan, The Role of Sintering in the Synthesis of Luminescence Phosphors, Sintering of Ceramics - New Emerging Techniques, InTech, Rijeka, 2012, pp 323-356. 